\title{
DETERMINATION OF THE NATIVE ANGLES OF GLENOID AND HUMERUS HEAD VERSION OF ADULT SKELETONS AT KARAD, MAHARASHTRA, INDIA
}

Avantika Bamne.

*Assistant Professor, Department of Anatomy Index Medical College, Hospital \& Research Centre, Indore, India.

\section{ABSTRACT}

Background: Several researchers have investigated the angles of Glenoid version and Humerus head version worldwide, however sparsely studied in India. The purpose of the study was to determine the native angles of Glenoid and Humerus head version of adult skeletons and to compare the observation with the findings of other workers in different races while discussing our finding in light of literature. This data would prove of great assistance at the time of actual shoulder replacement surgery for proper alignment and fixation of the implants, as any variance from normal version would alter gleno-humeral mechanics and may predispose to instability and arthropathy.

Materials and Methods: A total of sixty seven adult wet scapulae and sixty three humeri were harvested from cadavers fixed in formalin from the Department of Anatomy BJGMC, Pune. The angles of glenoid and humeral head version were measured using goniometer and compass. Correlation analysis was performed between humeral head version and glenoid version values.

Results: This study finds wide distribution of glenoid version ranging from -10 o to $+6^{\circ}$ the mean glenoid version of the left side $(n=34)$ was $-1.00 \pm 4.06^{\circ}$ and on the right side $(n=33)$ was $-3.30 \pm 3.63^{\circ}$ the average humerus version recorded on left $(n=31)$ and the right $(n=32)$ sides were $36.13 \pm 7.61^{\circ}$ and $37.56 \pm 7.8^{\circ}$ respectively.

Conclusion: We report a significant difference between the mean value of the glenoid version angle of both sides; right being greatly retroverted. A significant positive. Correlation was established between Glenoid version and Humerus head version on the right side.

KEY WORDS: Humerus head Version, Glenoid Version, Arthroplasty, Retroversion, Glenoid fossa.

Address for Correspondence: Dr. Avantika Bamne, Assistant Professor, Index Medical College, Hospital \& Research Centre, Indore, India. Mobile no: 9427350988

E-Mail: researchguide86@gmail.com

\section{Access this Article online}

Quick Response code Web site: International Journal of Anatomy and Research

ISSN 2321-4287

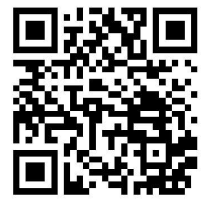

DOI: $10.16965 /$ ijar.2017.452

www.ijmhr.org/ijar.htm

Received: 19 Sep 2017

Peer Review: 20 Sep 2017

Revised: None
Accepted: 20 Oct 2017

Published (O): 01 Dec 2017

Published (P): 01 Dec 2017

\section{INTRODUCTION}

The gleno-humeral joint is the most mobile joint in the body. This wide range of motion makes the shoulder joint unstable, an instability compensated for by rotator cuff muscles, tendons, ligaments and the glenoid labrum. As the head of the humerus is larger than the glenoid fossa, only part of the humeral head can be in articulation with the glenoid fossa in any position of the joint. The vertical diameter of the glenoid is $75 \%$ and the transverse diameter is about $60 \%$ of the humeral head. In $75 \%$ of subjects, the glenoid fossa is retro tilted in relationship to the plane of the scapula. This relationship is important in maintaining horizon- 
tal stability of the joint and counteracting tendency toward anterior displacement of the humeral head [1-3]. The posterior tilt of the glenoid fossa, together with the posterior tilting of humeral head, provides a relationship that also counteracts the tendency toward horizontal instability [4]. Why is version important? Glenoid version is of interest in understanding normal shoulder biomechanics and pathological conditions inclusive of instability, arthritis, and developmental dysplasia. Any variance from normal version alters gleno-humeral mechanics and may predispose to instability and arthropathy.

Researchers have adapted different methods and tools to measure the versions; measurements on dry bone specimens, roentgenograms, 2D and 3D imaging Computed tomography. As an universal method for all shoulder bones fracture or replacement surgery the contra-lateral parameters are considered as a template for correction, however there is enough literature evidence that high inter-specimen and side specific variability exists [5-7]. This study therefore is an attempt to evaluate the native version of glenoid and humeral head in the Indian population which would prove useful at the time of actual shoulder replacement surgery.

Objectives of the present study are to determine the angles of Glenoid and Humerus head version, to compare the values of Glenoid and Humerus head version between right and left shoulders and to find the correlation between Glenoid version and Humerus head version values.

\section{MATERIALS AND METHODS}

Present Study was performed at Department of Anatomy, Krishna Institute of Medical Science Karad, Maharashtra, India. Ethical clearance was taken from the institutional ethics board. Adult wet Scapulae and Humeri were harvested from embalmed human cadavers fixed in formalin from the department of Anatomy, B J Medical College, Pune. Prior written consent was obtained and legal documentation was completed by the body donors, expressing self-willingness to donate their body for medical education and research purpose. Institute Ethics committee approval was obtained for current research work.
Scapulae: Total sixty seven; thirty four of the left and thirty three of right sides were studied.

Humeri: Total sixty three; thirty one of left and thirty two of right sides were studied.

Inclusion Criteria: All adult wet scapulae and humeri of both sexes were included. Age varied from sixty to eighty years.

Exclusion Criteria: The bones showing any apparent pathology, features of osteoarthritis and fractures were discarded from the study.

Methodology: The periarticular muscles and the soft tissue were stripped off to expose the Glenohumeral joint. The shoulder bones were disarticulated and angles were measured. Glenoid Version (GV) is the orientation of glenoid in transverse plane of the scapula [8]. Scapula was held fixed on mount with blade of scapula perpendicular to floor and the angle between the line connecting the most anterior and posterior point of the glenoid and the line perpendicular to floor was recorded with Goniometer.

Anterior tilt indicates anteversion and posterior tilt indicates retroversion (anteversion is denoted by positive while retroversion by negative sign). Humerus Head version (HHV) is the angle formed by humerus epicondyle axis and head axis. Head axis which is the longitudinal axis joining the superior and inferior most points on articular margin of anatomical neck was marked. HHV angle was measured using the technique described by Edelson [6] where in disarticulated humerus was mounted on wall with anterior tangent to the trochlea parallel to wall, and the angle between wall and humerus head axis was measured using a compass.

Each dimension was recorded three times and the mean was considered.

Statistical analysis: Data obtained was analysed using Bio-Medical Data Processor (BMDP new system 2) and applying appropriate statistical tests (Table 1) the mean and standard deviation of the various parameters were calculated. The obtained data was compared with other worldwide osteological studies.

\section{RESULTS}

Glenoid and Humerus head version values have been summarized (Table 1) Glenoid Version 
(GV) The values of glenoid version( $n=67)$ showed wide distribution in our study ranging from -10 을 to $+6^{0}$ The mean glenoid version of the left side recorded was $-1.00^{\circ} \pm 4.06^{\circ}$ and on the right side was $-3.30^{\circ} \pm 3.63^{\circ}$ Out of the thirty four left glenoids investigated twenty one glenoids were retroverted, eleven were anteverted while two were Neutrally positioned close to $0^{\circ}$ accounting for $72 \%$ of retroverted glenoids ( $63 \%$ of the glenoids version ranged from $-5.4^{0}$ to $-1^{0}$ and $9 \%$ were in the range $-5.4^{\circ}$ to $\left.-8.8^{\circ}\right) 21 \%$ anteverted ranging from $+3.6^{\circ}$ to $+5^{\circ}$ while $5.8 \%$ were almost neutrally positioned.

Twenty five glenoids were retroverted, three were anteverted and five were neutral positioned among thirty three right glenoids studied accounting for $76 \%$ retroverted glenoids ( $52 \%$ showed angle between $-5.3^{\circ}$ to $-1^{\circ}$ and $24 \%$ ranged between $-10^{\circ}$ to $-5.3^{\circ}$ ) while fifteen percent almost neutral positioned.

On comparison of glenoid version of both sides the right glenoid showed statistically significant greater retroversion, $(p>0.05)$. Humerus Head Version (HHV): The HHV of both sides $(n=63)$ varied from $20^{\circ}$ to $50^{\circ}$; the mean $\mathrm{HV}$ of both sides being $36.85^{\circ} \pm 7.72^{\circ}$ The average HHV on left side $(n=31)$ recorded was $36.12 \pm 7.61^{\circ}$ and $37.56^{\circ} \pm 7.89^{\circ}$ on right side. Fifty percent of the left Humeri were retroverted to an angle between $37.1^{\circ}$ and $45.6^{\circ} ; 19 \%$ ranged from $28.6^{\circ}$ to $32.8^{\circ}$ and nineteen percent from $20^{\circ}$ to $28.6^{\circ}$.

Table 1: Various outline of results.

\begin{tabular}{|c|c|c|c|}
\hline Parameter & N & $\begin{array}{c}\text { Mean } \pm \text { SD } \\
(\mathrm{mm})\end{array}$ & Range (mm) \\
\hline \multicolumn{4}{|c|}{ Glenoid version (degree) } \\
\hline Both & 67 & $2.13 \pm 3.99$ & -10.00 to $6 \mathrm{deg}$ \\
\hline Left & 34 & $-1.00 \pm 4.06$ & -10.00 to $6 \mathrm{deg}$ \\
\hline Right & 33 & $-3.30 \pm 3.62$ & -10.00 to $5 \mathrm{deg}$ \\
\hline \multicolumn{4}{|c|}{ Humerus head-version (degree) } \\
\hline Both & 63 & $36.85 \pm 7.72$ & 20 to $50 \mathrm{deg}$ \\
\hline Left & 31 & $36.12 \pm 7.61$ & 23 to $50 \mathrm{deg}$ \\
\hline Right & 32 & $37.56 \pm 7.89$ & 20 to $50 \mathrm{deg}$ \\
\hline
\end{tabular}

The average Right HHV $(n=32)$ recorded was $36.12 \pm 7.61^{\circ}$ and $37.56^{\circ} \pm 7.89^{\circ}$ Twenty nine percent of the right humeri ranged between $37^{\circ}$ and $41.3^{0} ; 22 \%$ between $28.6^{\circ}$ and $33^{\circ} ; 19 \%$ from $45.7^{\circ}$ to $50^{\circ}$ while $9 \%$ between 20 o to $28.6^{\circ}$. On comparison of version of both sided humeri the average right $\mathrm{HHV}$ recorded was higher, but did not show very statistical significant difference $(p \leq 0.05)$ A significant positive co relation was established between Glenoid version and Humerus head version on the Right side value of ' $r$ ' $=0.456$ The $p$ value was 0.0087 the result is significant (at $p<0.01$ ) On the Left side though a positive correlation between the GV and HHV was seen, value of ' $r$ ' $=0.325$ the correlation was not significant $p=0.079$ (at $p<0.01$ ).

\section{DISCUSSION}

The glenoid version is the orientation of glenoid in transverse plane of the scapula. The glenoid cavity angle in the Indian population has not been explored adequately. The values of glenoid version showed wide distribution in our study ranging from $-10^{\circ}$ to $+6^{\circ}$ The mean version recorded on left side was $-1.00 \pm 4.06^{\circ}$ and on the right was $-3.30 \pm 3.63^{\circ}$ Right glenoids were found to be more retroverted concurring to the findings reported by Uma S et al [9] who studied hundred dry scapulae of each side using Image J software and have noted a mean glenoid angle on the left $-5.02 \pm 2.07^{\circ}$ and $6.90 \pm 3.48^{\circ}$ on the right with a significant difference in the glenoid version of both sides.

Nyffeler et al [10] studied the effects of glenoid component version on humeral head displacement and joint reaction forces where they implanted shoulder prosthesis in neutral version in 6 cadaveric shoulders and when the glenoid version changed to $4^{\circ}$ towards more anteversion and retroversion, resulted in anterior and posterior translation of the humeral head subsequently leading to eccentric loading of the of the glenoid. Thus precise assessment of glenoid component version would help prevent loosening and instability of implant Cyprien et al [4] conducted a radiographic study to compare the glenoid version of 50 healthy shoulders and 15 shoulders with chronic dislocation. They reported a significant difference in the glenoid retroversion of healthy $\left(7.1^{0} \pm 4.6\right.$ left and $8^{\circ} \pm$ 5.0 right $)$ and chronic dislocating $\left(8.9^{\circ} \pm 5.6\right.$ left and $13.2^{\circ} \pm 4.0$ right) shoulders and a higher retroversion on the right side.

The version is altered or exaggerated in presence of glenohumeral pathology like osteoarthritis, rotator cuff tears leading to glenoid wear and bone loss and is associated 
with instability and ultimately dislocation of the joint. Gordon Edelson [6] studied the variations in the retroversion of 336 dry bone specimens of humeri head from varied ethnical groups. The angle in the Americans $(n=28)$ was $32.6^{\circ} \pm 7.97$ on the right humeral head and $28.0^{\circ} \pm 7.64^{\circ}$ on the left humeral head. They noted the northern Chinese $(n=28)$, Alaskan Eskimo $(n=27)$ and New Mexican Indian $(n=29)$ specimens had greater retroversion angles. The mean retroversion angle for northern Chinese specimens was $46.4^{\circ}$ $\pm 11.1^{\circ}$ on the right and $42.7 \pm 13.1^{\circ}$ on the left. The mean retroversion angle in New Mexican Indian specimens was $41.4 \pm 9.50^{\circ}$ on the right side and $39.4^{\circ} \pm 9.16$ on the left. Humeral retroversion was high in children aged between 4 months to 4 years; $65.6^{\circ}$ on the right and $65.1^{\circ}$ on the left. At average 8 years humerus derotated to fall within high-side adult parameters. Overall rotation appears to be substantially completed by the age of 16 years. Our observations concurred with Gordon Edelson ${ }^{6}$ where in high right humeral head version was noted. N Matsumura et al [11] evaluated 410 normal shoulders from healthy volunteers for humeral head version and glenoid version on computed tomography scans; reported an average humeral head version of average of $26^{\circ} \pm$ $11^{\circ}$ and glenoid version of $1^{\circ} \pm 3^{\circ}$ Both humeral head retroversion and glenoid retroversion were significantly higher on the dominant side and in men than in women in their study. They also emphasised humeral head version and glenoid version values well co related with those of the contralateral shoulder.

\section{CONCLUSION}

The Glenoid and Humerus version shows a wide range of variation in different geographical distribution, in men and women and on the right and left side of same individual. In our study the right Glenoids and Humeri were found to be more retroverted probably being high-demand dominant shoulders. A significant positive co relation was established between Glenoid version and Humerus head version on the right side This data may prove helpful for establishing criteria for anatomical restoration in shoulder surgery Researchers have adapted different methods and tools to measure the versions; careful interpretation of the data is therefore essential.

\section{Conflicts of Interests: None}

\section{REFERENCES}

[1]. Sarrafian SK: Gross and functional anatomy of the shoulder. Clin Orthop 1983;173:11-18.

[2]. Saha AK: Dynamic stability of the glenohumeral joint. Acta Orthop Scand 1971;42:491-505.

[3]. Saha AK: Mechanics of elevation of glenohumeral joint: Its application in rehabilitation of flail shoulder in upper brachial plexus injuries and poliomyelitis and in replacement of the upper humerus by prosthesis. Acta Orthop Scand 1973;44:668-678.

[4]. Cyprein JM, Vasey HM et al.Humeral retrosion and glenohumeral relationship in normal shoulder and in recurrent anterior dislocation (scpulometry) Clin orthop Relat Res:1983;8-17.

[5]. Robertson DD, Yuan J, Bigliani LU, Flatow EL, Yamaguchi K. Three-dimensional analysis of the proximal part of the humerus: relevance to arthroplasty. J Bone Joint Surg Am 2000;82:1594-602.

[6]. Edelson $\mathrm{G}$. Variations in the retroversion of the humeral head. J Shoulder Elbow Surg 1999;8:142-5.

[7]. Pearl ML, Volk AG. Coronal plane geometry of the proximal humerus relevant to prosthetic arthroplasty. J Shoulder Elbow Surg1996;5:320-6.

[8]. Churchill RS, Brems JJ, Kotschi H. Glenoid size, inclination, and version: An anatomic study. J Shoulder Elbow Surg 2001;10:327-332.

[9]. Uma SV, BalasubramanyamV. Rettroversion angle of Glenoid cavity in South Indian population, National Journal of Clinical Anatomy 2016;5:22-27.

[10]. Richard W. Nyffeler, Ralph Sheikh, Effects of glenoid component version on humeral head displacement and joint reaction forces: An experimental study J Shoulder Elbow Surg. 2006;15(5):625-9.

[11]. Noboru Matsumura, Kiyohisa Ogawa, MD Shuzo Kobayashi, MD Morphologic features of humeral head and glenoid version in the normal glenohumeral joint Journal of Shoulder and Elbow Surgery. 2014Volume 23;11,1724-1730.

How to cite this article:

Avantika Bamne. DETERMINATION OF THE NATIVE ANGLES OF GLENOID AND HUMERUS HEAD VERSION OF ADULT SKELETONS AT KARAD, MAHARASHTRA, INDIA. Int J Anat Res 2017;5(4.3):4707-4710. DOI: 10.16965/ijar.2017.452 